Bulhões, T.G.; Bulhões, N.G.; Gontijo, B.M. O Ecoturismo em Santo Antônio do Itambé (MG) como indutor do envolvimento comunitário no entorno de Unidades de Conservação. Anais do IX Congresso Nacional de Ecoturismo e do V Encontro Interdisciplinar de Turismo em Unidades de Conservação. Revista Brasileira de Ecoturismo, São Paulo, v.6, n.4, nov-2013, pp.45-62.

\title{
O Ecoturismo em Santo Antônio do Itambé (MG) como indutor do envolvimento comunitário no entorno de Unidades de Conservação
}

\author{
The Ecotourism in Santo Antônio Itambé (MG, Brazil) as an inducer of \\ community involvement in the surroundings of Protect Areas
}

\section{Tainá Gonçalves Bulhões, Nauê Gonçalves Bulhões, Bernardo Machado Gontijo}

\begin{abstract}
RESUMO
Este artigo visa refletir sobre a forma com que o ecoturismo induz o envolvimento das comunidades localizadas no entorno de Unidades de Conservação, considerando que elas são criadas com intuito, também, de uso público, no qual o turismo se enquadra e é visto pelo governo como importante ação para preservação das Unidades de Conservação e valorização das culturas das comunidades de seu entorno. É proposto o estudo de caso da pequena cidade de Santo Antônio do Itambé para observar a influência da visibilidade do ecoturismo no Parque Estadual do Pico do Itambé ao envolvimento comunitário. A metodologia perpassa pela elaboração do referencial que sustentou, nessa pesquisa, o plano teórico metodológico orientado pela pesquisa qualitativa, sendo ele acerca do histórico Parque em questão e levantamento das teorias e publicações sobre o ecoturismo e o envolvimento comunitário com a atividade. Como forma de coleta de dados, foi utilizada à pesquisa de gabinete e bibliográfica, a observação assistemática e a aplicação de entrevistas, com a realização de quatro visitas em campo nos anos de 2009, 2010 e 2012. O resultado desse trabalho indicou que o desenvolvimento do ecoturismo na cidade tem se transformado em objetivo comum para o futuro econômico e cultural da comunidade, contudo o ecoturismo ainda não foi capaz por si só de induzir o envolvimento comunitário. Todavia a atividade se encontra em estagio inicial havendo possibilidade de reverter à postura dos sujeitos a tempo de se envolverem, apropriarem e planejarem o turismo.
\end{abstract}

PALAVRAS-CHAVE: Ecoturismo; Envolvimento Comunitário; Unidade de Conservação; Santo Antônio do Itambé.

\begin{abstract}
This article aims to reflect on the way that ecotourism induces the involvement of communities located around the protected areas, considering that they are created with the intention also of public use, where tourism fits and is seen by the government as important action to preserve the protected areas and appreciation of the cultures of the communities surrounding it. It is proposed by a casa study of the small town of Santo Antônio do Itambé to observe the influence of the visibility of ecotourism in the State Park Pico Itambé in the community involvement. The methodology goes through the preparation of reference, in this research, the theoretical methodology guided by qualitative research, it is about the park and its historic and about theories and publications on ecotourism and community involvement with the activity. As a means of data collection was used to desk research and literature, the systematic observation and interviews with people involved in the State Park. Was done four visits to Santo Antônio do Itambé, in the years 2009, 2010 and 2012. The result of this study indicated that the development of ecotourism in the city has been transformed into common goal for the economic and cultural future in the community, however ecotourism has not been able by itself to induce community involvement. However the activity is in initial stage with the possibility of reversing the position of the subject in time to get involved, take ownership and plan tourism.
\end{abstract}

KEYWORDS: Ecoturism; Community Envolvement; Protected Areas; Santo Antônio do Itambé. 
O Ecoturismo em Santo Antônio do Itambé (MG) como indutor do envolvimento comunitário no entorno de Unidades de Conservação

\section{Introdução}

A cidade de Santo Antônio do Itambé, pertence à microrregião de Conceição do Mato Dentro no estado de Minas Gerais, e está localizada na divisa com a microrregião do Vale do Jequitinhonha. Distante 17 quilômetros da cidade do Serro, $110 \mathrm{~km}$ de Diamantina e $350 \mathrm{~km}$ de Belo Horizonte.

Segundo o IBGE (2010) o município possui 4.135 habitantes, sendo que apenas $29 \%$ residem na área urbana. Sua economia baseia-se no setor de serviços, com expressão para o mercado informal, autônomo e pluriativo. Entretanto, a influência da agropecuária, principalmente no molde familiar, para economia local se mantém representativa, principalmente no que tange à segurança alimentar das famílias.

As cidades desses limiares do Jequitinhonha, incluindo Santo Antônio do Itambé mantêm características típicas ao interior mineiro que moldam sua ruralidade, e a economia ligada à agropecuária, além da manutenção de expressões culturais típicas ao ambiente rural, como relações de maior proximidade e intimidade com os outros, valorização dos saberes e fazeres, e uma expressiva relação de territorialidade e de aproximação com o meio natural (BULHÕES, 2013).

O município pertence à Serra do Espinhaço, também conhecida como cordilheira e cadeia, que inicia em Minas Gerais e adentra a Bahia até a divisa com o Piauí. É em Santo Antônio do Itambé que se localiza o Pico do Itambé, ápice do Espinhaço e constitui um grande divisor entre as bacias hidrográficas do centro-leste brasileiro e a do Rio São Francisco (COMIG; IGC/UFMG, 1997 apud MONTEIRO, 2011). Segundo Saadi (1995, apud MONTEIRO, 2011), a denominação "serra" esconde uma realidade fisiográfica que é mais bem definida pelo termo "planalto".

A cidade se dispõe entre os rios Preto e Branco. A denominação desses rios se dá pela característica de suas águas. O primeiro mais amarronzado, mesmo sendo uma água límpida e transparente, e o Rio Branco com águas mais claras. Os dois rios se encontram dentro da cidade formando o Rio Guanhães, afluente da sub-bacia do Santo Antônio, que por sua vez corre para o Rio Doce. Devido à característica geológica da cidade e a presença desses rios, Santo Antônio do Itambé possui dezenas de cachoeiras, cânions e mirantes.

O Pico do Itambé é um importante marco da paisagem do noroeste mineiro e foi um valioso ponto de referência dos primeiros desbravadores do território brasileiro, em virtude de sua magnitude. A presença marcante da Serra do Espinhaço proporciona à região grande visibilidade para a atividade turística.

A Serra do Espinhaço recebeu da Organização das Nações Unidas para a Educação, a Ciência e a Cultura (UNESCO), em 2005, o título de "Reserva da Biosfera Mundial" que confere um diferencial ao município. O título da UNESCO também reconhece a necessidade de amparo à região, no que diz respeito à sua proteção, referência recorrente entre os cientistas como Gontijo (2008). 
Se não tomarmos cuidados quanto à preservação do que ainda resta de biodiversidade na Cadeia do Espinhaço e em seus biomas adjacentes, estaremos na eminência de sofrer um grande "terremoto ambiental" já que estamos, como mostra a geografia de nossa "tectônica ambiental", localizados bem em cima de seu hipotético epicentro (GONTIJO, 2008, p.13).

O processo de ocupação humana ao longo da história provocou a fragmentação da vegetação nativa do Espinhaço. O elevado valor ambiental da Serra do Espinhaço confronta sua alta relevância econômica, principalmente para a mineração, agroindústria e, atualmente, para a silvicultura, atividades com impactos ambientais expressivos.

A atenção para a proteção do Espinhaço por meio das Unidades de Conservação (UCs) vem desencadeando uma nova dinâmica territorial ao Jequitinhonha, e logo, também, em Santo Antônio do Itambé. A concepção de UCs introduziu não apenas um novo formato de produção do espaço como também o discurso da atividade turística como opção acessível e condizente para manutenção e substituição econômica desses territórios.

A lei no 9.985 de julho de 2000 instituiu o Sistema Nacional de Unidades de Conservação (SNUC) com objetivos de contribuir para a manutenção da diversidade biológica, proteger as espécies ameaçadas de extinção, colaborar para a preservação e a restauração de ecossistemas naturais, promover o desenvolvimento sustentável a partir dos recursos naturais e a utilização dos princípios e práticas de conservação da natureza no processo de desenvolvimento, entre outros. O SNUC define Unidades de Conservação (UCs) como

O espaço territorial com limites definidos, que possuam características naturais relevantes e importantes recursos ambientais, incluindo as águas jurisdicionais, com objetivos de conservação, legalmente instituído pelo Poder Público e sob regime especial de administração, apropriadas à sua proteção, e as divide em duas categorias, as Unidades de Proteção Integral e as de Uso Sustentável, esta permite o uso direto de seus recursos naturais, ou seja, a exploração sustentável, social e economicamente viável dos recursos ambientais (SNUC, 2000).

Neste sentido, o turismo vem sendo tratado como uma das principais alternativas seja no âmbito social ou seja no âmbito econômico, para promover o desenvolvimento de diversas localidades que se encaixam no mesmo contexto, o de criação de uma Unidade de Conservação, como é o caso de Santo Antônio do Itambé (BULHÕES, 2013).

\section{Parque Estadual do Pico do Itambé}

Criado em 21 de janeiro de 1998, através do Decreto № 39.398 do Governo Estadual de Minas Gerais, o Parque Estadual do Pico do Itambé - PEPI visa proteger as riquezas naturais em seu domínio, como cachoeiras, cursos d' água e vegetação única. A exploração sustentável do ecoturismo e a realização de pesquisas científicas se enquadram 
O Ecoturismo em Santo Antônio do Itambé (MG) como indutor do envolvimento comunitário no entorno de Unidades de Conservação

nos objetivos desta Unidade de Conservação (STCP, 2004).

Segundo o plano de manejo elaborado pela STCP (2004) a área do parque está distribuída entre os municípios de Santo Antônio do Itambé (2.926 ha), Serro (930 ha) e Serra Azul de Minas (840 ha). A maior área de abrangência territorial, a portaria principal e a sede administrativa do PEPI estão no município de Santo Antônio do Itambé. Observa-se que grande parte da influência das transformações socioespaciais da cidade foram exercidas pela criação do PEPI e pela visibilidade turística do mesmo (BULHÕES, 2013).

Para o Estado de Minas Gerais a criação deste Parque traz uma série de benefícios, por exemplo, fica assegurada a proteção das cabeceiras de duas importantes bacias hidrográficas, dos rios Jequitinhonha e Doce e a indução ao turismo, na Figura 1 é possível ver as áreas protegidas adjacentes ao PEPI.

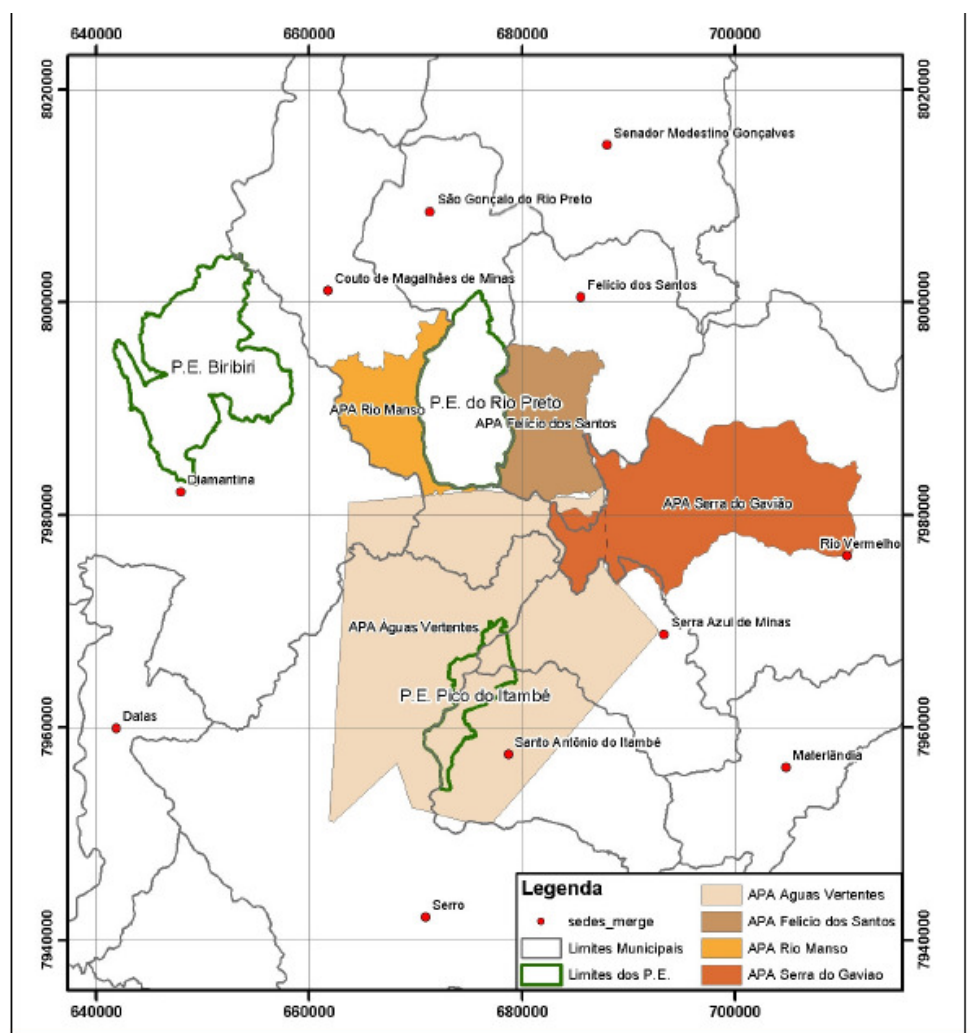

Figura 1: UCs adjacentes ao PEPI. Fonte: STCP (2004).

Figure 1: Protects Areas adjacent to the PEPI. Source: STCP (2004).

Forjadas no imaginário urbano, tendo como referência a dicotomia sociedade/ natureza, aparecem, em especial, as unidades de conservação de proteção integral, que demandam a retirada de antigos moradores de seu interior para a preservação da natureza. Comumente, essas unidades são materializadas em espaços rurais, sobre- 
pondo-se a territórios materiais e imateriais constituídos historicamente pelas comunidades que ali habitam (MONTEIRO, 2011).

O PEPI se enquadra na categoria de Unidade de Proteção Integral. Nesta categoria está assegurada a proteção integral dos recursos hídricos e minerais, da fauna e da flora, sendo permitida a exploração do turismo sustentável e a pesquisa científica (SNUC, 2000). De acordo com o SNUC os Parques - Nacional, Estadual ou Natural Municipal dependendo do âmbito de sua criação - integram a categoria mais restrita, as Unidades de Proteção Integral - são de posse e domínios públicos e têm

(...) como objetivo básico a preservação de ecossistemas naturais de grande relevância ecológica e beleza cênica, possibilitando a realização de pesquisas científicas e o desenvolvimento de atividades de educação e interpretação ambiental, de recreação em contato com a natureza e de turismo ecológico (SNUC, 2000).

Segundo Aldibert (2004) estas áreas restringem ou impossibilitam a utilização pelos atores locais dos recursos naturais ali existentes, esses atores também demonstram desinteresse e desconhecimento acerca das UCs o que remete à problemática da falta de envolvimentos da comunidade na atuação do Parque e de outras atividades, como o turismo, que podem substituir as práticas agora proibidas.

A criação do PEPI levou para Santo Antônio do Itambé a efetivação da legislação e fiscalização ambiental o que representou, praticamente, a extinção de suas principais atividades econômicas. A exploração de mata nativa para produção e venda de carvão e a extração de areia, principal suporte para a construção civil no município, foram diretamente afetadas. A extração de lenha, de minerais e de matériaprima para confecção de artesanato, a caça, o garimpo também sofreram repressões com a criação do PEPI (ALMEIDA et al., 2012).

Esse contexto de conflitos já é amplamente observado no âmbito das UCs e as comunidades do entorno. O principal meio que tem sido apontado para redução destes conflitos é a gestão participativa e o envolvimento comunitário. O turismo, por meio do ecoturismo, é então, observado como principal objetivo comum entre o PEPI e a comunidade por se conceber como opção econômica e via de desenvolvimento do município e como meio para educação ambiental e preservação do ecossistema protegido, já que o ecoturismo determina "entre seus princípios a conservação ambiental aliada ao envolvimento das comunidades locais, devendo ser desenvolvido sob os princípios da sustentabilidade, com base em referenciais teóricos e práticos, e no suporte legal' (BRASIL, 2010, p.11)

O turismo foi colocado como principal opção econômica, o que influencia os moldes culturais do Jequitinhonha e de Santo Antônio do Itambé. A atividade turística tem foco central em grande parte das expectativas de alternativa econômica da comunidade, contudo a atividade ocorre de forma pontual, a maior parte dos turistas não visita a cidade, vai exclusivamente ao Parque. 
O Ecoturismo em Santo Antônio do Itambé (MG) como indutor do envolvimento comunitário no entorno de Unidades de Conservação

O turismo realizado nas UCs pode então se transformar em uma ferramenta capaz de envolver a comunidade tanto na gestão participativa do PEPI, de forma a reduzir os conflitos de interesses, quanto no planejamento da atividade, como forma de permitir a divisão justa das divisas e benefícios gerados?

Este artigo, por tratar apenas de um recorte dessa situação não poderá responder concretamente a tal pergunta, mas a observação do ocorrido em Santo Antônio do Itambé poderá nortear uma resposta.

\section{Ecoturismo e o Envolvimento Comunitário}

A compreensão sobre o fenômeno turístico se dá como consequência do seu entendimento como trocas e encontros entre os sujeitos e deles com o espaço. Tem-se o turismo como uma atividade que se desenvolve no espaço, produzindo-o e reproduzindo-o e, também, promovendo o movimento de pessoas para vários lugares, em busca de consumi-los (RODRIGUES, 1997).

Para Bedim (2008) as forças produtivas que envolvem o turismo não apenas intervém como recriam modos de organização socioespacial. O turismo, enquanto esfera produtiva diferenciada, "provoca a coexistência, a (des)integração ou a superposição de distintas formas de relações de produção, engendrando e acentuando desigualdades a partir dos diferenciados ritmos de desenvolvimento" (BEDIM, 2008, p.28).

A articulação produtiva que define a prestação de serviços diretos ou indiretos ligados ao turismo, agregam-se a processos sociais, costumes, espaços, indivíduos e grupos humanos - os quais possuem ritmos diferenciados de transformação na história, assim como a formação econômico-social que os envolve (BEDIM (2007). O turismo é, em si, um fenômeno social moderno nascido das contradições da própria maquinaria produtiva da modernidade. Assim Bedim (2007) o considera produto do processo histórico moderno, se inserindo entre as inúmeras concepções da modernidade e suas tendências econômicas, políticas, culturais e ambientais a transformar o mundo.

Traz consigo a importância da era moderna na experiência ocidental; signo de um mundo sem fronteiras, porém delimitado em si; a compressão tempo-espaço a produzir contradições ao reduzir as distâncias aparentes entre os homens e os últimos 'refúgios naturais' da Terra (BEDIM, 2007).

O turismo pode ser considerado uma atividade essencialmente humana, pois a viagem cria intrínsecas relações do resultado do encontro entre os visitantes e os autóctones. Caracteriza ainda uma prática social, pois oportuniza a união de culturas, trocas de experiências, satisfação de desejos, busca de emoções e formas de aprendizagem diante do novo. Neste sentido, o turismo compõe juntamente com o lazer, a cultura, as atividades artísticas, a melhoria da qualidade de vida e o hedonismo, um "novo estilo de vida" caracterizado por elementos que visam cada vez mais à supremacia do indivíduo (RODRIGUES, 1997, apud ZAMIGNAN; SAMPAIO, 2010). 
Deve-se considerar, ainda que inserida em um contexto global urbano, que a cultura ocidental se afastou, devastou, e às vezes até negou, seus ambientes naturais e costumes tradicionais ao se destinar interesse e valor à urbanidade e à tecnologia disseminando padrões globais vemos o surgimento da pós-modernidade. Que aponta a revalorização da cultura rural e de expressões arcaicas, mais simbólicas e de maior proximidade com a natureza. Devemos perceber que o turismo faz uso dessa tendência, já que ele se torna um dos responsáveis por essa reaproximação, podendo ocasionar em resultados positivos ou negativos. E é a partir das UCs que se tem pautado o turismo de natureza no Brasil.

\begin{abstract}
Vale destacar que, inicialmente, a criação de parques nacionais tinha como objetivo principal o desenvolvimento do turismo e de atividades de lazer. Eram instituídos como símbolos da identidade nacional, no intuito de contribuir para a divulgação do país no exterior e para abrigar remanescente do patrimônio florestal nacional (SCALCO, 2009, p.71).
\end{abstract}

Contudo, devido às características globalizantes e dominadoras do modelo econômico mundial o turismo representa, cada vez mais, acúmulo de divisa e o acréscimo econômico. Isso gera como consequência a transformação de expressões culturais e dos espaços em produtos altamente comercializáveis. As Unidades de Conservação, hoje, representam um potencial atrativo para o desenvolvimento do ecoturismo, sobretudo quando se trata das UCs da categoria Parque. Segundo Medeiros et al. (2011), a visitação nos Parques do Brasil tem potencial para gerar entre $R \$ 1,6$ biIhão e $R \$ 1,8$ bilhão por ano, considerando as estimativas de fluxo de turistas projetadas para o país (cerca de 13,7 milhões de pessoas) até 2016. O ecoturismo é um negócio. É um negócio lucrativo. E de risco, alto risco, sendo conceituado pelo Ministério do Turismo como

(...)um segmento da atividade turística que utiliza, de forma sustentável, o patrimônio natural e cultural, incentiva sua conservação e busca a formação de uma consciência ambientalista por meio da interpretação do ambiente, promovendo o bem-estar das populações (BRASIL, 2010, p.17).

Devemos considerar alguns fatores para compreender porque o turismo em áreas naturais deve estimular o envolvimento comunitário como forma de efetivar seu desenvolvimento e a distribuição de seus benefícios. Como vimos o Brasil tem norteado o desenvolvimento do turismo de natureza para UCs, todavia estas além de apresentarem conflitos socioambientais com as comunidades de seu entorno, não foram completamente implantadas, muitas não possuem plano de manejo nem finalização da regularização fundiária.

Frente ao quadro de conflitos gerados é fundamental pensar em alternativas que visem compatibilizar as distintas formas de uso e apropriação dos recursos naturais, 
O Ecoturismo em Santo Antônio do Itambé (MG) como indutor do envolvimento comunitário no entorno de Unidades de Conservação

por parte dos diferentes grupos sociais envolvidos. No caso da relação entre as comunidades e os Parques o principal uso possível é o turismo. Por isso a importância do envolvimento comunitário com intuito de apropriação do desenvolvimento do ecoturismo na cidade, Para o Ministério do Turismo "o envolvimento comunitário, principalmente em áreas protegidas, é fundamental para a conservação e uso sustentável dos recursos naturais e o sucesso do desenvolvimento do Ecoturismo" (BRASIL, 2010, p.71)

\section{Metodologia}

Com intuito de alcançar os objetivos propostos, primeiramente foi realizada a pesquisa bibliográfica, presente no embasamento teórico deste trabalho e, posteriormente, o estudo de caso que se enquadra na proposta da pesquisa, de caráter qualitativo.

Na busca da reflexão sobre a possibilidade do ecoturismo induzir o envolvimento comunitário em Santo Antônio do Itambé e ao tentar explicar isso em termos de significado e significância, ou seja, por meio da busca do esclarecimento sobre a natureza do mundo vivido, a fim de compreender as transformações socioespaciais locais. Para isso é imprescindível o conhecimento da vida cotidiana, conforme proposto por Lefebvre (2008).

Dessa forma, o estudo de caso será o método utilizado, já que segundo Dencker (2000, p.127) "é o estudo profundo e exaustivo de determinados objetos ou situação. Permite o conhecimento em profundidade dos processos sociais". Para a construção das considerações acerca do estudo de caso se fez necessário à realização de visitas ao município e observação dos fatos ou fenômenos para obter informações quanto a realidade local. A observação é considerada uma coleta de dados para conseguir informações sobre determinados aspectos da realidade. Ela ajuda o pesquisador a "identificar e obter provas a respeito de objetivos sobre os quais os indivíduos não têm consciência, mas que orientam seu comportamento" (LAKATOS, 1996 apud QUARESMA, 2005).

As imersões ocorreram nos anos de 2009, 2010 e por duas vezes em 2012. Nos dois primeiros anos a ida a cidade foi impulsionada pelo lazer, contudo veio a se fundamentar como o método não formal da pesquisa, proposto por Lefébvre (2008), já que foram estas visitas que impulsionaram a investigação sobre o tema neste local. Diversas percepções surgiram e alguns questionamentos perpassaram pela busca de entendimento quanto à falta de interação percebida entre o PEPI e a comunidade, mesmo com tamanha proximidade física entre eles, a compreensão das possibilidades do desenvolvimento do turismo tanto pelo potencial local quanto pela necessidade de novas fontes de renda a um município de caráter humilde. A demonstração das expectativas locais em torno da atividade turística, obtida pelas conversas informais, demostraram que mesmo presente no discurso o turismo ainda é incipiente no município, mas desencadeia uma dinâmica própria de influência à transformação socioespacial. 
Tornou-se imprescindível identificar as percepções dos atores locais sobre esse processo. Esses dados foram obtidos através das entrevistas, pois elas se relacionam com os valores, as atitudes e as opiniões dos sujeitos entrevistados, dados que a pesquisa bibliográfica e a observação não subsidiam. Foi feito uso do método de entrevista com alguns tópicos de história de vida.

As entrevistas semiestruturadas, segundo Quaresma (2005), é muito utilizada quando se deseja delimitar o volume das informações, obtendo, assim, um direcionamento maior para o tema, intervindo a fim de que os objetivos sejam alcançados.

As entrevistas foram aplicadas em dois momentos do ano de 2012 não foram embasadas em dados amostrais por ser uma pesquisa de cunho qualitativo. Sobre esse aspecto Valles (1997 apud MURTA, 2009, p.56) afirma que "as técnicas quantitativas fixam a priori o desenho amostral da pesquisa, enquanto na realidade qualitativa o investigador esta impedido de determinar previamente o numero de entrevistas necessárias à sua investigação".

Não possuindo um cálculo amostral nem determinando um número de sujeitos, é feito uso de duas técnicas para fechar o número de entrevistas. Para o contato com os sujeitos a serem entrevistados, se fez uso da técnica "bola de neve", seguindo a sugestão de Murta (2009), embasada por Godoi e de Mattos (2006), segundo a qual

O acesso aos entrevistados deve organizar-se através de uma técnica, denominada "bola de neve" pelas redes sociais naturais. A captura pelos sujeitos participantes da amostra se dá por meio de amigos, parentes, contatos pessoais e conhecidos. Visando evitar uma ruptura entre os momentos da vida cotidiana e a elaboração dos discursos na entrevista (GODOI; DE MATTOS, 2006 apud MURTA, 2009, p.56).

Para que o resultado das entrevistas permitisse a conquista do objetivo proposto, de refletir sobre o turismo como indutor do envolvimento comunitário de Santo Antônio do Itambé, foi delimitado na técnica bola de neve grupos de sujeitos relevantes à temática. Portanto os atores locais (sujeitos reconhecidos pela comunidade como relevantes no município, sujeitos engajados no desenvolvimento da atividade turística e aqueles que porventura não entram na "bola de neve"), os órgãos públicos locais (escola, prefeitura - secretária de turismo e meio ambiente, de educação e associação municipal dos produtores rurais), os sujeitos do PEPI (gerente e funcionários) e os sujeitos diretamente atingidos por ele (reassentados).

Em março de 2012 foram realizadas 12 entrevistas. A relação dos entrevistados por grupos de sujeitos entrevistados, anteriormente definido, se vê na Figura 2. 


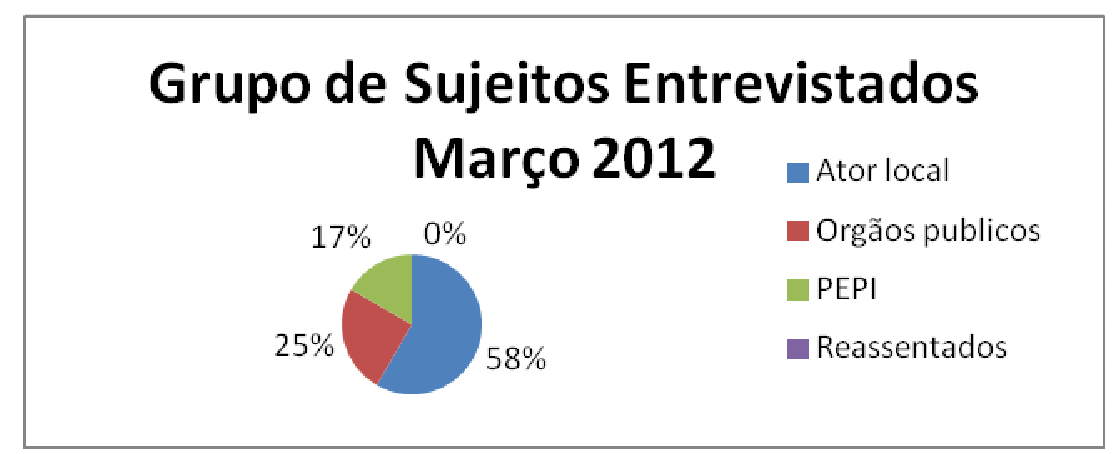

Figura 2: Gráfico da porcentagem de entrevistas - março de 2012 - por grupo de sujeitos.

Figure 2: Graph of the percentage of interviews - march 2012 - by subject group.

Fonte: elaboração própria (2012). Source: Authors (2012).

No segundo momento foram realizadas 19 entrevistas, todavia não feito uso da fala de todos na analise do trabalho, para evitar a repetição, mas também dar ênfase aos discursos que melhor podem contribuir. Vale atentar que todas as representações se fazem presente por contribuírem para a realização desta reflexão. A relação de entrevistados por grupo de sujeitos está apresentada na Figura 3.

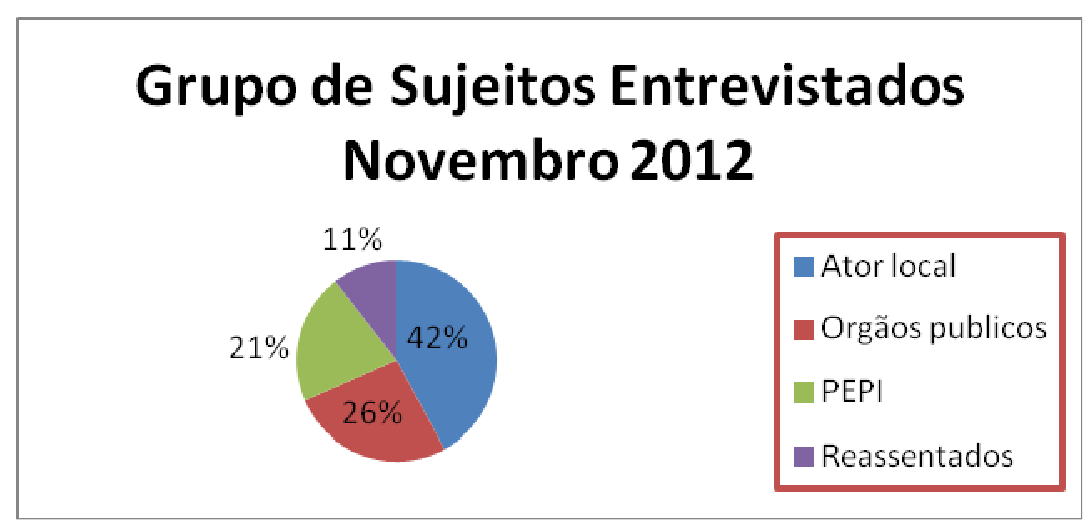

Figura 3: Gráfico da porcentagem de entrevistas realizadas em novembro de 2012 por grupo de sujeitos. Figure 3: Graph of the percentage of interviews conducted in November 2012 by a group of subjects.

Fonte: elaboração própria (2012). Source: Authors (2012).

Por meio da entrevista foram alcançados dados de duas naturezas. Um deles é chamado de objetivo ou concreto (dados que podem ser obtidos através de outras fontes como censos, estatísticas, registros civis e outros) de referência aos fatos de transformação espacial originada pelo PEPI, como as datas de criação, o número de famílias afetadas e os impactos sociais gerados. O outro, denominado de subjetivo, inclui dados que se referem diretamente ao indivíduo entrevistado, isto é, suas atitudes, valores e opiniões. São informações ao nível mais profundo da realidade e que só podem ser 
Bulhões, T.G.; Bulhões, N.G.; Gontijo, B.M.

conseguidos com a contribuição dos atores sociais envolvidos (MINAYO, 1993).

Como última etapa da pesquisa o estudo das informações recolhidas por meio da observação e dos resultados das entrevistas propostas permitiu a realização da reflexão indicada no objetivo deste trabalho. Oferecendo como resultado o entendimento sobre a indução do envolvimento comunitário a partir da criação de um Parque, bem como o desenrolar dessa influência e as perspectivas de futuro dessa comunidade, à luz da percepção local.

\section{Ecoturismo e suas consequências para envolvimento comunitário em Santo Antônio do ltambé}

A iniciativa de criação do PEPI partiu do então prefeito de Santo Antônio do Itambé, Antônio Augusto Gonçalves Neto e por isso, inicialmente, o projeto possuiu apoio da comunidade local. Foi ele quem mobilizou as prefeituras de Serro Azul de Minas e Serro para aderirem à ideia, mas manteve as principais infraestruturas do PEPI para o seu município, facilitando a visibilidade turística da cidade do Itambé, com a instalação da sede e da portaria principal do parque.

O prefeito conquistou a comunidade com a promessa da indução do turismo como alternativa de renda e de resolução rápida das questões fundiárias para legalização das terras do PEPI. E deve-se considerar que a iniciativa teve cunho governamental muito voltado para o recolhimento e repasses de recursos.

O ICMS Ecológico passou a ser um instrumento para beneficiar os municípios que priorizam saneamento básico e as Unidades de Conservação. Com relação ao subcritério Unidades de Conservação, o Governo compensa os municípios que abrigam em seu território, UC federais, estaduais, municipais e particulares, após cadastramento junto ao IEF e mediante aprovação do Conselho Estadual de Política Ambiental - COPAM (STCP, 2004).

O repasse do ICMS Ecológico, leva em consideração o percentual da área do município ocupada pela UC, sendo mais bem remunerado pelas áreas que possuem maiores restrições de uso, em função da necessidade de sua proteção ambiental. Este instrumento acaba sendo um grande incentivador para os municípios mineiros buscarem a criação de Unidades de Conservação.

Contudo, não foi necessário muito tempo para que as consequências do PEPI atingissem a comunidade mais negativa do que positivamente. Sua criação levou para Santo Antônio do Itambé a efetivação da legislação e fiscalização ambiental o que representou, praticamente, a extinção de suas principais atividades econômicas: exploração de mata nativa para produção e venda de carvão e a extração de areia, principal suporte para a construção civil no município, foram diretamente afetadas. A extração de lenha, de minerais e de matéria-prima para confecção de artesanato, a caça, o garimpo também sofreram repressões com a criação do PEPI (ALMEIDA et al., 2012). 
O Ecoturismo em Santo Antônio do Itambé (MG) como indutor do envolvimento comunitário no entorno de Unidades de Conservação

Apresento abaixo dois discursos, resultado das perguntas que abordaram a criação do PEPI e as impressões locais.

O ano não sei, mais ou menos, 2005, 2002, aproximadamente. Eu não guardo data. A maioria encarou péssimo né. Por quê? Porque se caçava, se destruía né. Os animais, as matas. Com a entrada do parque a área preservada não pode ser violada (Ator local - poder público).

Aconteceu... que muitos já pegou e "ah porque esse parque, o pessoal, só vem pra fazer a gente passa fome, não deixa a gente roçar, que não deixa garimpa, que não deixa fazer nem aquilo." Né, pegou achar ruim. Mas agora eles já tão concordando, já tá vendo, assim, o trabalho que a gente tá fazendo tá sendo valorizado, entendeu? Tá valendo a pena a gente fazer o trabalho. Eu mesmo gosto de fazer (Ator local - reassentado e funcionário do PEPI).

A cidade recebeu o projeto pioneiro do IEF de regularização fundiária e reassentamento para UCs, que teve início em 2007. Segundo Lara (2009), para a implantação do parque, 27 famílias que residiam no interior da área tiveram que ser removidas e indenizadas, houve surgimento de conflitos devido a natural resistência dos moradores, por causa de seus modos tradicionais rurais, em deixar a terra em que nasceram e de onde extraíam o sustento.

$\mathrm{Na}$ negociação, parte das famílias foi indenizada, os demais moradores estão sendo reassentados em uma fazenda adquirida pelo IEF nas redondezas. Mas o processo de regularização ainda não foi concluído e mantêm diversos transtornos às famílias diretamente atingidas. As casas construídas foram padronizadas e não levaram em conta as características de cada família, algumas ainda não possuem água e ainda não foram entregues (ALMEIDA et al., 2012).

Atentamos para o fato de que o município ainda não apresenta uma infraestrutura adequada para a efetivação da atividade turística. Mas, o seu relevante potencial deve ser lembrado, ao considerar o acréscimo da busca e deslocamento urbano para espaços de natureza abundante, quanto pelo resgate e manutenção cultural, interação e conservação ambiental. Nesse cenário é observado que a comunidade cria expectativas de crescimento para a cidade por meio do turismo, mas não é capaz de realizar de fato, ações que concretizem suas vontades e expectativas, devido as imposições burocráticas e financeiras. Abaixo é destacado uma passagem retirada das entrevistas que trata desta consideração.

Itambé eu vejo o seguinte. Itambé é uma cidadezinha como é... Várias cidadezinhas de Minas Gerais, porém com potencial turístico muito grande. Potencial ecológico muito grande. E. o Itambé a....16 anos atrás começou a mudar aqui muito. Começou a crescer economicamente falando. O comércio deu uma melhorada. Só que é... eu acredito que é...de uns anos pra cá deu um decliniozinho, retrocedeu um pouco. Então a cidade hoje acho que ela tá muito a desejar em questão de estrutura. 
Falando no turismo então a cidade tá ai sem bases descentes. Sem estrutura nenhuma pra receber o turista hoje. Nós temos um potencial turístico muito grande que são várias cachoeiras. Tem hoje o Parque Pico do Itambé que tá em implantação, tá em fase de implantação, mas vai ser. Com fé em Deus. É um dos grandes atrativos nossos aqui. (...) Eu acredito que aqui a gente tem mais potencial que a maioria das cidades. São várias cachoeiras, o acesso é fácil né. O que eu acho que nós precisamos aqui hoje é trabalhar mais nossos recursos humanos aqui. Trabalhar mais o pessoal para receber o turista e tirar proveito disso (Ator local - produtor rural).

Contudo, mesmo havendo imparcialidade para resolução do conflito da regularização fundiária é possível perceber que, em sua maioria, a população de Santo Antônio do Itambé reconhece os benefícios da criação do PEPI, tanto os que tangem as melhorias ambientais, quanto às expectativas sobre o turismo, que é baseado nas suas atrações naturais, como rios, cachoeiras, PEPI e o Pico do Itambé. Foram selecionadas duas falas que apresentam isso.

Diminuiu bastante fogos. Tinha épocas ai que era muito fogo...muito incêndio. Já diminuiu bastante. Você vê que a vegetação já tá diferente...porque o parque já tá...já tão fechando o parque, então já tá dando controle. E mais fiscalização no entorno então já tem sim muita melhoria (Ator local - professora).

Hoje o povo já entende que não pode. Então já melhorou muito essa parte do Parque Estadual. E eu penso assim que futuramente que o povo vai entender muito melhor. Porque trouxe oportunidade né...assim funcionários...pessoas que tem esclarecimento que entendem né e fizeram cursos e que podem explicar pra gente. Pra população. O valor do parque. Então hoje eu acho que o povo já entende. Tá se educando mais e já entende que não pode depredar as coisas da natureza. Então eu vejo uma coisa muito boa ter criado o parque do Itambé (Ator local - idosa).

Mas, mesmo com esse reconhecimento, ainda são incipientes as ações conjuntas para conquista de objetivos comuns. Sobre essa falta de envolvimento trago as passagens abaixo

O parque é o seguinte, ele faz parte assim, principalmente da cidade, e outra, tanto o Parque precisa da comunidade, como o pessoal precisa do Parque. Porque o Parque é uma vida nova, é uma área, principalmente a água, a comunidade igual Santo Antônio do Itambé, que as água toda nasce do Parque. Todo mundo serve, o pessoal serve na rua e com a água do parque, de dentro do parque. Só que tem muitas coisas que precisa de fazer no parque pra ajudar né e a comunidade é assim meia parada, muitas horas não dá, assim, valor muito pra ajudar o parque ter uma coisa melhor (Ator local - PEPI). 
O Ecoturismo em Santo Antônio do Itambé (MG) como indutor do envolvimento comunitário no entorno de Unidades de Conservação

Hoje, há 14 anos da criação do Parque Estadual do Pico do Itambé, é possível perceber certa esperança nos discursos coletados, e parte aqui apresentados, os quais muitas vezes estão associados ao relato do estranhamento, causado pela criação do PEPI. Há, entretanto, o reconhecimento de alguns benefícios gerados pela sua criação, como a regularização fundiária, a contratação de mão-de-obra local e as expectativas geradas pelo turismo.

A perspectiva criada pelo PEPI em Santo Antônio do Itambé inclui as influências regionais que 0 atingem, as expectativas geradas por essas influências à comunidade local e pela dificuldade de se aplicar ações concretas para efetivá-las. O passo mais importante, para que Santo Antônio do Itambé consiga se beneficiar do turismo, é que ele cresça junto com o PEPI e a partir de sua comunidade local. Para isso, é preciso que os sujeitos se mobilizem e que hajam efetivamente para conquistarem o pertencimento ao processo turístico e à nova função que espaço tem assumido.

\section{Considerações finais}

A introdução do turismo como elemento chave para o desenvolvimento da economia local surge motivada por alguns fatores. O principal deles, por ser o que exerceu influência direta no município, foi a criação do Parque, conforme mostrado anteriormente. Mas também se deve considerar que a atividade turística está sendo incentivada em todo entorno de Santo Antônio do Itambé. Cidades como Diamantina e Serro já possuem visibilidade não só no cenário do turismo mineiro, como no nacional. Santo Antônio do Itambé está inserida no Circuito dos Diamantes e na área de influência da Estrada Real, os moradores começam utilizar da atividade turística como fonte de renda e de expectativas de melhora na qualidade de vida, outros passaram a trabalhar no próprio PEPI.

A estruturação do PEPI o transforma em um atrativo relevante para alavancar o turismo em Santo Antônio do Itambé, mas a cidade e sua comunidade precisam acompanhar e participar dessa estruturação para que se engajem e se apropriem integralmente, se tornando responsáveis por todo processo de desenvolvimento do turismo.

Dessa forma, o turismo pode sim, ser um elemento capaz de induzir o envolvimento comunitário em prol do planejamento participativo da atividade e a distribuição de seus benefícios. Contudo deve-se atentar para a ineficiência na participação dos principais meios coletivos para o planejamento e gestão do PEPI e turismo no município. O conselho consultivo do PEPI e o Conselho Municipal de Turismo - COMTUR são as principais formas de aproximação da comunidade com as decisões de planejamento dos mesmos e apresentam baixa efetividade. Todavia, a participação da comunidade, como um todo, ainda é incipiente, bem como uma integração entre o planejamento municipal e do PEPI, logo não houve a construção de objetivos comuns e aplicação de planejamentos participativos efetivos.

O turismo é o elemento potencial para o crescimento econômico e social e para promover o envolvimento comunitário de Santo Antônio do Itambé, mas devemos re- 
lembrar do caráter excludente e seletivo dessa atividade, portanto, se não houver a apropriação local dessa oportunidade, a cidade corre risco de se tornar mais um refúgio natural construído por investimentos externos.

No caso de Santo Antônio do Itambé a carência está na educação, na capacitação profissional, na falta de orientações para associativismo e no incentivo a participação popular para organização comunitária. Estes seriam meios de auxiliar a comunidade a assumir uma postura ativa na tomada de decisão e apropriação da sua realidade local. A fala a seguir sintetiza e introduz a reflexão do vir-a-ser do município.

Eu gosto demais da minha terra que é aqui Santo Antônio do Itambé. Nasci lá praticamente no pé do pico. Onde tem muita água...muita planta né. Então no meu tempo de criança eu olhava pra Serra do Itambé nem sabia o que que era aquilo né. Via aquela serra e não significava nada. Mas hoje eu acho que significa tudo né...é um ponto assim turístico. É o motivo que traz muitas pessoas de fora. A gente já sabe o significado dele mesmo...pra natureza... mesmo pra assim pra ecologia né. Porque é o motivo das pessoas entenderem o significado das plantas e tudo que fica envolta dele. Até porque foi criado o parque estadual. Aí tem a chefe lá do IEF que esclarece. Faz palestra. Leva as crianças lá. Aí o povo já vai entendendo o valor né. As crianças que antigamente já todo pássaro que via ia matar né...hoje eles já tão entendendo que não pode fazer isso. Não pode queimar né. Antigamente o povo queimava demais. O povo plantava bastante aqui no município, mas era tudo assim aquela agricultura ainda atrasada né. Porque o povo queimava, era tudo...não tinha. Hoje o povo já entende né porque tem uma coisa pra frear um pouco. Explicar o que não pode né. Acho muito importante né. Acho que é o motivo também né, o que nos temos. As belezas naturais que a gente tem, tem o pico as cachoeiras. São motivos pra atrair assim as pessoas os visitantes. $E$ acho que essa parte de turismo vai melhor muito também (Ator local - professora aposentada).

O vir-a-ser de Santo Antônio do Itambé deve passar pela concepção de mecanismos de mobilização e de participação, que podem conferir a conquista de uma autogestão comunitária, tanto do turismo quanto econômica e social. Porém, para isso é necessário criar condições de capacitação dos sujeitos, para que possam estar mais preparados para participação, de fato, nas discussões. O devir de Santo Antônio do Itambé caminha para a destinação turística da cidade, contudo esse caminho deve ser construído coletivamente, por todos os atores produtores desse espaço, visto o potencial que o turismo representa.

Cabe ressaltar a afirmação de Rudolf Steiner - fundador da Antroposofia, da Pedagogia Waldorf, dentre outros - "A natureza faz do homem um ser natural. A sociedade faz dele um ser social. Somente o homem é capaz de fazer de si um ser livre". Acredita-se então que se deve incentivar o engajamento das comunidades envolvidas com o propósito da preservação ambiental. Dessa forma chama-se atenção para a 
O Ecoturismo em Santo Antônio do Itambé (MG) como indutor do envolvimento comunitário no entorno de Unidades de Conservação

necessidade do incentivo a autonomia, liderança, a pro-atividade da comunidade. A conquista do homem livre pode ser garantida pelo caminho do reconhecimento e pertencimento ao lugar, seus significados e significâncias, como forma de buscar um futuro desejado pelos e para os itambeanos.

\section{Referências bibliográficas}

ALMEIDA, F.B.; BULHÕES, T.G.; SILVA, K.F. Turismo no espaço rural: um olhar sobre a comunidade Santo Antônio do Itambé (MG). Anais do XII Encontro Nacional de Turismo com Base Local. Re-vista Brasileira de Ecoturismo, São Paulo, v.5, n.4, nov2012, p.823.

AUDIBERT, E.A. Preservar com ou sem presença humana? - A problemática ambiental no contexto de áreas protegidas. Porto Alegre: Instituto de Filosofia e Ciências Humanas de UFRGS, 2004.

BRASIL. Lei $\mathbf{n}^{\circ}$ 9.985, de 18 de julho de 2000. Regulamenta 0 art. 225, parágrafo $1^{\circ}$, incisos I, II, III e VII, da Constituição Federal, institui o Sistema Nacional de Unidades de Conservação e dá outras providências. Brasília, 2000.

BRASIL. Ministério do Turismo. Ecoturismo: orientações básicas. / Ministério do Turismo, Secretaria Nacional de Políticas de Turismo, Departamento de Estruturação, Articulação e Ordenamento Turístico, Coordenação Geral de Segmentação. 2. ed. Brasília: Ministério do Turismo, 2010.

BEDIM, B.P. O espaço capitalista da natureza e seu (contra)uso turístico: a dialética da visitação pública em áreas protegidas: um ensaio teórico. Caderno Virtual de Turismo, vol. 7, núm. 3, 2007, pp. 75-89. Universidade Federal do Rio de Janeiro. Río de Janeiro, 2007. Disponível em: http://redalyc.uaemex.mx/redalyc/ pdf/1154/115416285008.pdf. Acesso em: 26/10/2012.

BEDIM, B.P. O processo de intervenção social do turismo na Serra de Ibitipoca (MG) [manuscrito]: simultâneo e desigual, dilema camponês no "Paraíso do Capital" / Bruno Pereira Bedim. - 2008. Disponível em: <http://www.bibliotecadigital.ufmg.br/ dspace/bitstream/handle/1843/MPBB-7MDM8U/

bruno bedim mestrado ufmg turismo ibitipoca.pdf?sequence=1> Acesso em: 26106/2013.

BULHÕES, T.G. Transformações Socioespaciais e Ruralidade no Entorno de Unidades De Conservação: um olhar para Santo Antônio do Itambé/MG. Monografia, Instituto de Geociências - Universidade Federal de Minas Gerais, Belo Horizonte, 2013.

CHIZZOTTI, A. A Pesquisa Qualitativa nas Ciências Humanas e Sociais: evolução e desafios. Portugal: Revista Portuguesa de Educação. Ano/vol 16, num 002, 2003. Disponível em: http://redalyc.uaemex.mx/pdf/374/37416210.pdf. P. $221-236$.

CORIOLANO, L.N.M.T. O turismo comunitário no nordeste brasileiro. Anais do V Seminário da Associação Nacional de Pesquisa e Pós-graduação em Turismo- Anptur, 2008. Belo Horizonte, MG. 
GONÇALVES, R.N. (sup.). Diagnóstico Ambiental da Bacia do Rio Jequitinhonha: diretrizes gerais para a ordenação territorial. Salvador: Ministério do planejamento e orçamento e Instituto Brasileiro de Geografia e Estatística - IBGE, 1997.

GONTIJO, B.M. Uma geografia para a Cadeia do Espinhaço. In: Megadiversidade Cadeia do Espinhaço: avaliação do conhecimento científico e prioridades de conservação. Belo Horizonte: Conservation International, vol. 4, n. 12, 2008, p. 7-16.

IBGE. Censo Demográfico 2010. Disponível em: http://www.censo2010.ibge.gov.br/ sinopse/index.php?dados=26\&uf=31\#topo piramide. Acesso em: 20 de fevereiro de 2012.

LARA, M. Acordo preserva natureza do Parque Estadual do Pico do Itambé. Belo Horizonte: Estado de Minas, 19 de julho de 2009. Disponível em: http:// wwo.uai.com.br/UAl/html/sessao 2/2009/07/19/

em noticia interna,id sessao=2\&id noticia $=119288 /$ em noticia interna.shtml

LEFEBVRE, H. A Revolução Urbana. Belo Horizonte: Ed. UFMG, 1999.

LEFEBVRE, H. Espaço e Politica. Belo Horizonte: Editora UFMG, 2008.

MONTEIRO, F.T. Parque Nacional das Sempre-vivas (MG): travessias e contradições ambientais. UFMG: Belo Horizonte, 2011.

MINAYO, M.C.S. O desafio do conhecimento científico: pesquisa qualitativa em saúde. 2a edição. São Paulo/Rio de Janeiro: Hucitec-Abrasco, 1993.

MURTA, I.B. “A gente é dono e não é": representações sociais em torna da atividade turística e do processo de patrimonialização em São Bartolomeu (MG). Belo Horizonte: UFMG, 2009.

QUARESMA, V.B.; JUREMA, S. Aprendendo a entrevistar: como fazer entrevistas em Ciências Sociais. Revista Eletrônica dos Pós-Graduandos em Sociologia Política da UFSC. Vol. 2 o 1 (3), janeiro-julho/2005, p. 68-80. Disponível em: www.emtese.ufsc.br. Acesso em: 07/02/2011.

SCALCO, R.F. Desafios, Paradoxos e Complexidade na Gestão do Mosaico de Unidades de Conservação da Área de Proteção Ambiental Cachoeira das Andorinhas Ouro Preto/MG. Dissertação (Mestrado em Geografia) - Programa de Pós Graduação em Geografia, Universidade Federal de Minas Gerais, Belo Horizonte, 2009.

STCP ENGENHARIA DE PROJETOS LTDA. Plano de Manejo do Parque Estadual do Pico do Itambé. Encarte 2 - análise da região da unidade de conservação - SDS02/02 - Diamantina 2004b.

STCP ENGENHARIA DE PROJETOS LTDA. Plano de manejo do Parque Estadual do Pico do Itambé: encarte 2 - análise da região da unidade de conservação sds01/02 - revisão final. Curitiba, 2004. 
O Ecoturismo em Santo Antônio do Itambé (MG) como indutor do envolvimento comunitário no entorno de Unidades de Conservação

ZAMIGNAN, G.; SAMPAIO, C.A.C. Turismo de Base Comunitária como Perspectiva para a Preservação da biodiversidade e de Modos de vidas de comunidades tradicionais: a Experiência da micro-bacia do rio sagrado, Morretes (pr). Anais do V Encontro Nacional da Anppas, Florianópolis: 2010. Disponível em: http://www.anppas.org.br/encontro5/ cd/artigos/GT1-142-147-20100809214216.pdf. Acesso em: 27/08/2012.

Tainá Gonçalves Bulhões: Universidade Federal de Minas Gerais, Belo Horizonte, MG, Brasil.

Email: taina_gbulhoes@yahoo.com.br

Link para o currículo Lattes: http://lattes.cnpq.br/6772228461686706

Nauê Gonçalves Bulhões: Universidade Federal dos Vales do Jequitinhonha e Mucuri , Diamantina, MG, Brasil.

Email: nauegb@gmail.com

Link para o currículo Lattes: http://lattes.cnpq.br/7010523049833393

Bernardo Machado Gontijo: Universidade Federal de Minas Gerais, Belo Horizonte, MG, Brasil.

Email: gontijobm@yahoo.com.br

Link para o currículo Lattes: http://lattes.cnpq.br/0882015654292509

Data de submissão: 28 de junho de 2013

Data de recebimento de correções: 28 de junho de 2013

Data do aceite: 01 de setembro de 2013

Avaliado anonimamente 